\title{
Application of Resource Efficient and Cleaner Production (RECP) in the Energy Intensive Industry to Promote Low Carbon Industrial Development in Bangladesh
}

\author{
Tahazzud Hossain \\ Junior Environmental Specialist, Environment Department, Safeguard Division, ACE Consultants Ltd., \\ Dhaka, Bangladesh \\ Email: tahazzud esbd@yahoo.com
}

Received 15 June 2015; accepted 18 August 2015; published 21 August 2015

Copyright (C) 2015 by author and Scientific Research Publishing Inc. This work is licensed under the Creative Commons Attribution International License (CC BY). http://creativecommons.org/licenses/by/4.0/

(c) (i) Open Access

\section{Abstract}

The consumption of natural resources (e.g. raw material, water \& energy) in the industries is bringing welfare to the society but per unit of product from the industry is linked with the generation of environmental pollutants and emissions. Resource constraints and climate crisis have come into focus globally; particularly it has become one of the major concerns in the Asia Pacific region. At present, the countries in the Asia Pacific use resources three times greater than the rest of the world to generate one unit of GDP. These countries are more vulnerable to the impacts of resource constraints and climate change. Resource Efficient and Cleaner Production (RECP) has come as a preventive environmental measure to facilitate pollution prevention and reduce carbon intensity per unit of products along with financial profit of the industry. Bangladesh has been considered as one of the transition economies in the South Asia. Industrial sector supports second largest share to the GDP of Bangladesh. The industrial productivity in the country is solely dependent on the locally available natural gas and imported raw materials. Energy Efficiency (EE) and Cleaner Production (CP) measures in the industry can facilitate the promotion of low carbon industrial development through pollution prevention and energy conservation. The main objective of this research is to identify the policy instruments for the promotion of low carbon industrial development in Bangladesh within RECP framework. In this research, ceramics sector has been taken as a research unit. Based on the research objective, three research strategies have been followed which are: 1) review of the existing Environmental Policy, Industrial Policy and Energy Policy of Bangladesh, 2) review of the relevant measures adopted in the regional countries, and 3) case study in a ceramic industry. Stakeholder consultation has been conducted to identify appropriate policy instruments based on multi-criteria evaluation. Through this research, eleven policy instruments have been identified in connection with the promotion of RECP measures in the 
country with the target of developing low carbon industrial operation. Among the eleven policy instruments seven policy instruments have been identified as prioritized policy instruments based on multi-criteria evaluation through stakeholder consultation. Apart from the prioritized policy instruments the Government of Bangladesh (GoB) has to make realistic sector wise policies and specific policy targets to be achieved within timeline. The GoB has to increase consistency among the policies, strengthen coordination among the relevant institutions, and apply mix of policy instruments.

\section{Keywords}

Cleaner Production, Low Carbon Industry, Policy Instrument, Pollution Prevention, Resource Efficient

\section{Introduction}

\subsection{Background}

In the planet of limited natural resources with higher need of consumption to boost economic growth where it has become a major challenge to ensure such a consumption pattern of resources that creates less environmental pressure. There is a question whether greenhouse gases (GHGs) emissions have been decoupled from the economic growth and industrial production? From the point of view of energy use in the industry it can be said that yes there is great influence on GHG emissions due to increased industrial activities since the source of energy for industrial production is still now dominated by fossil fuels. It has been estimated that there was $12 \mathrm{GtCO}_{2}$-eq (25\% of all GHGs) emissions from industrial sector globally in 2005 (IPCC, 2007). A strong correlation between material consumption and energy related $\mathrm{CO}_{2}$ emission has been found by research and it has been shown that growing levels of resource consumption implies increased $\mathrm{CO}_{2}$ emissions [1]. Their results show that material metabolism and energy-related $\mathrm{CO}_{2}$ emissions are closely linked across emerging economies at different development stages and with very different levels of per capita GDP. In the study, it has been said that if no effective policies are implemented that drastically increase resource efficiency, growth in GDP per capita may result in an almost linear growth of material consumption and energy related $\mathrm{CO}_{2}$ emissions. They concluded that increasing resource efficiency can be a key strategy to achieve the objective of making future economic growth in Asia "greener" and to further decouple growth from material consumption and energy related $\mathrm{CO}_{2}$ emissions.

Resource Efficient and Cleaner Production (RECP) is a pathway planned to facilitate efficient use of resources (e.g. raw materials, water and energy) to prevent environment pollution and reduce carbon emission from the industrial activities. RECP has also been planned to help enterprises to do more with less providing more value with less environmental impact and better economic and ecological efficiency. Therefore, RECP is considered as one of the key approaches to low carbon industry. Low carbon industry ensures reduction of energy intensity and GHG emissions through dematerializing of products, increasing process efficiency, minimizing process emissions, switching to low carbon inputs and closing the carbon loop [2]. Policy-makers [3] and academic analysts [4] have recently argued that a low carbon transition could take the form of a "low carbon industrial revolution". The pathways of low carbon industry have synergy with the concept of Green Industry. Green industry ${ }^{1}$ being a part of the green economy ${ }^{2}$ strategy has been taken into consideration to ensure uninterrupted industrial growth with efficient use of materials and energy along with supporting climate change mitigation option. Hence, RECP has been defined as the continuous application of preventive environmental strategies to process, products and services to increase efficiency and reduce risks to humans and the environment [5].

\footnotetext{
${ }^{1}$ Green industry promotes sustainable patterns of production and consumption i.e. the patterns that are resource and energy efficient, low-carbon and low waste, non-polluting and safe, and which produce products that are responsibly managed throughout their lifestyle. The Green Industry agenda covers the greening of industries, under which all industries continuously improve their resource productivity and environmental performance (UNIDO Green Industry, Vienna, May 2011).

${ }^{2}$ Green economy has been defined as one that results in improved human well-being and social equity, while significantly reducing environmental risks and ecological scarcities. In its simplest expression, a green economy can be thought of as one which is low carbon, resource efficient and socially inclusive (UNEP, 2011).
} 
Rationale use of resources in the input process, reducing the loss of materials \& cost, reducing the pollution intensity, reusing and/or recycling the maximum of the primary inputs \& packaging materials and improving environmental performance over the industrial production processes are considered vital to build the foundation for new and more sustainable production model [6].

\subsection{Problem Statement}

Developing countries in the Asia-Pacific have obtained rapid economic growth in recent years brought about by globalization and export led growth. Bangladesh as a low income ${ }^{3}$ country in South Asia has achieved tremendous success in industrial growth. The Government of Bangladesh $(\mathrm{GoB})$ has the ambition to be a middle income country by 2021. Moreover, Goldman Sachs ${ }^{4}$ names Bangladesh in its list of "Next 11" countries (those most likely to become one of the world's largest economies after the BRIC ${ }^{5}$ nations) and the country is one of JP Morgan's "Frontier ${ }^{6}$ Five" economies. These predictions are based on the rapid economic growth facilitated by the rising industrial growth. In the fiscal year 2011-2012, the industrial sector provided the second largest share to Gross Domestic Product (GDP) in Bangladesh which was 31.26\% (Bangladesh Economic Review FY 2012-2013, MoF). Besides, the GoB has made a target to obtain 40\% share of the GDP from the industrial sector by 2021. The energy intensive manufacturing sector in Bangladesh includes chemicals (fertilizer), ceramics, cement, paper \& pulp, and iron \& steel industry. The main energy input in those energy intensive industries is natural gas which fully comes from domestic supply sources. The industrial sector is the second largest consumer (121.5 billion cubic meters) of the total natural gas production (708.90 billion cubic meters) in the fiscal year 2010-2011 of the country [7]. Eventually, the production of the manufacturing industries completely depends on the domestic natural gas supply. Hence, formulating appropriate policies with time befitting policy instruments are essential to reduce energy consumption in the manufacturing business (input-process-output) operation. Making the energy intensive industries low carbon intensive (e.g. through applying RECP strategy) will not only serve climate agenda (e.g. reduction of energy intensity and GHG emissions) but also bring financial benefit of the manufacturing business through operational cost savings and productivity, and after all serve environmental objectives (e.g. pollution prevention) and the society (e.g. improved human environment).

Bangladesh as a non-Annex-1 country has no GHG-emission reduction commitments within the frameworks of the international agreements. With a view to preventing environmental pollution and protecting the natural environmental in the country, the GoB has formulated legal and institutional framework. Under the legal framework Environmental Conservation Act (formulated in 1995) and Environmental Conservation Rules (formulated in 1997) have been formulated in connection with the National Environmental Policy (formulated in 1992) by the GoB. The Department of Environment (DoE) of GoB has been implementing the above legal frameworks along with other relevant policies, action plans and strategies under the Ministry of Environment and Forest (MoEF). The Ministry of Industry in the country has formulated an Industrial Policy where the provision of environmental protection has been illustrated. The Ministry of Power, Energy and Mineral Resources (MPEMR) has been following a National Energy Policy (formulated in 1995) and a Renewable Energy Policy (formulated in 2008). There are no policies relevant to Cleaner Production, Resource Efficiency and/or Energy Efficiency. Therefore, there are no direct bindings for the enterprises for efficient use of raw materials, water and energy. In the study report of IFC [8], absence of policy, lack of willingness of the enterprises and lack of access to finance have been identified as major barriers to promote energy efficiency in the industries of Bangladesh.

\subsection{Research Objective}

The objective of the research is to identify the policy instruments to support strengthening RECP practice in the existing industries and to implement RECP in the new industries to promote low carbon industrial development

\footnotetext{
${ }^{3}$ Per capita income in Bangladesh swells to US\$1044 (in the fiscal year 2012-2013) from the US\$923 (in the base year 2005-2006). The country with per capita incomeUS\$1035 falls under low income country as per the database of World Bank

(http://data.worldbank.org/about/country-classifications/country-and-lending-groups\#Low_income, accessed on 2 December 2013) whereas, the country with US\$1036-US\$4085 per capita income falls under lower middle income country.

${ }^{4}$ The Goldman Sachs Group, Inc. is leading global investment banking, securities and investment management firm (www.goldmansachs.com).

${ }^{5}$ BRIC nations include Brazil, Russia, India and China- top emerging economies labeled by Goldman Sachs

${ }^{6} \mathrm{JP}$ Morgan is a leading financial service provider institution (www.jpmorgan.com, accessed on 20 July 2013)
} 
in Bangladesh. For the sake of the research objective, energy intensive industries have been selected as the broader research area where ceramics sector has been planned to focus in this research work. Review of the existing policies, review of regional initiatives and case study in a large ceramic industry are the three objects for data collection. Multi-criteria evaluation (MCE) method has been used for the identification of the appropriate policy instruments. Stakeholder consultation has been conducted to support MCE of policy instruments. Recommendations have been provided for the formulation of policy instruments to promote low carbon industrial development in the country.

\subsection{Research Question}

With a view to achieving the above stated research objective one main research question and three sub research questions supporting the main research question have been made which are as follows:

Main Research Question-

What policy instruments can be applied to promote low carbon industrial development in Bangladesh?

Sub Research Questions-

1) What are the current policy instruments to promote low carbon industrial development in Bangladesh?

2) What are the measures related to the RECP framework adopted in the regional countries?

3) What are the current practices in terms of energy management in the ceramics manufacturing sector?

\section{Materials and Methods}

\subsection{Data Collection}

This research is a practice oriented research which will intervene to find out the policy instruments to promote low carbon industrial development in Bangladesh. Three research objects have been studied which are as follows:

1) Existing policies;

2) Measures adopted related to the RECP concept in the regional countries; and

3) Representative company in the Bangladesh ceramics industry.

The above three research objects have been studied through two research strategies to collect data. Desk research strategy has been applied to conduct the review of existing policies and the measures adopted related to the RECP concept in the three regional countries (Thailand, Vietnam and Philippines). Case study as a research strategy has been followed to evaluate the current energy management practices in a ceramic manufacturing company. After the study of the three objects applying two research strategies different policy instruments have been identified in connection with the promotion of low carbon industrial development in the country. Finally, multi-criteria have been applied to evaluate the identified policy instruments in order to find out the preferred policy instruments which can be applied to motivate the energy intensive industries towards the adoption of EE and CP measures which eventually answers the main research question. It has already mentioned that single case study has been chosen in this research because of limited timeframe of the research project. The researcher thinks that selection of several cases (e.g. several ceramics manufacturing companies) could provide better picture about the Energy Management practices in case of energy intensive industries in Bangladesh. The researcher also thinks that the participation of all the relevant stakeholders for multi-criteria evaluation of the policy instruments could provide more appropriate policy instruments for implementing EE and CP measures within RECP framework in Bangladesh.

\subsection{Data Analysis}

After the study of the three research objects (review of national policies, review of regional initiatives and case study), some data/information have been made. This information refers to the policy instruments. Based on the review of regional initiatives, case study and stakeholder consultation, some policy instruments have been identified through screening. The identified policy instruments are then evaluated based on multi-criteria (method applied by Konidari and Mavrakis [9]. Multi-criteria evaluation (MCE) of policy instruments has been done through stakeholder consultation. Finally, the most preferred policy instruments have been found out to promote low carbon industrial development within RECP framework in Bangladesh. Environmental performance, political acceptability and feasibility of implementation are the three main criteria based on which policy instruments 
have been evaluated. Each main criterion has also sub criteria (Figure 1). Each policy instrument has been evaluated based on the weighting value ( 3 for significant, 2 for moderate, 1 for low and 0 for insignificant) given for each sub criteria. Each stakeholder has filled up one MCE table. Policy instruments have been prioritized based on the maximum sum of weighting value given for each policy instrument.

\section{Results and Discussion}

\subsection{Existing Policy Instruments in Bangladesh}

There are sector wise policies such as National Environmental Policy (1992), National Energy Policy (1995) and Industrial Policy (2005) in Bangladesh. Under the National Environmental Policy the Government of Bangladesh has formulated the Environmental Conservation Act (1995) and the Environmental Conservation Rules (1997) along with other sector specific regulatory policies and voluntary strategies like 3R Strategy (2010). After the formulation of the National Environmental Policy the regulatory authority (Department of Environment) has applied environmental control and enforcement policy instruments to ensure that industries are complying with the national environmental standards. The Bangladesh Council for Scientific and Industrial Research (BCSIR) institute under the Ministry of Science and Technology has been conducting research on different industrial processes. This institute has also been doing research in ceramics, energy conservation, renewable energy, environmental pollution and in many other areas. In order to enhance the use of renewable energy technologies, the GoB has been providing fiscal incentives under the Renewable Energy Policy (2008). At present; the GoB does not provide any kind of subsidy and/or fiscal incentives for energy efficiency and cleaner production. The following three policy instruments are in practice in Bangladesh in terms of resource efficiency and cleaner production in the industries:

- Environmental Control \& Enforcement;

- Research \& Development; and

- Fiscal Incentives (only in promoting renewable energy technology).

\subsection{Barriers to Promote Low Carbon Industry}

Major Barriers to Promote Low Carbon Industry in Bangladesh within the RECP Framework are:

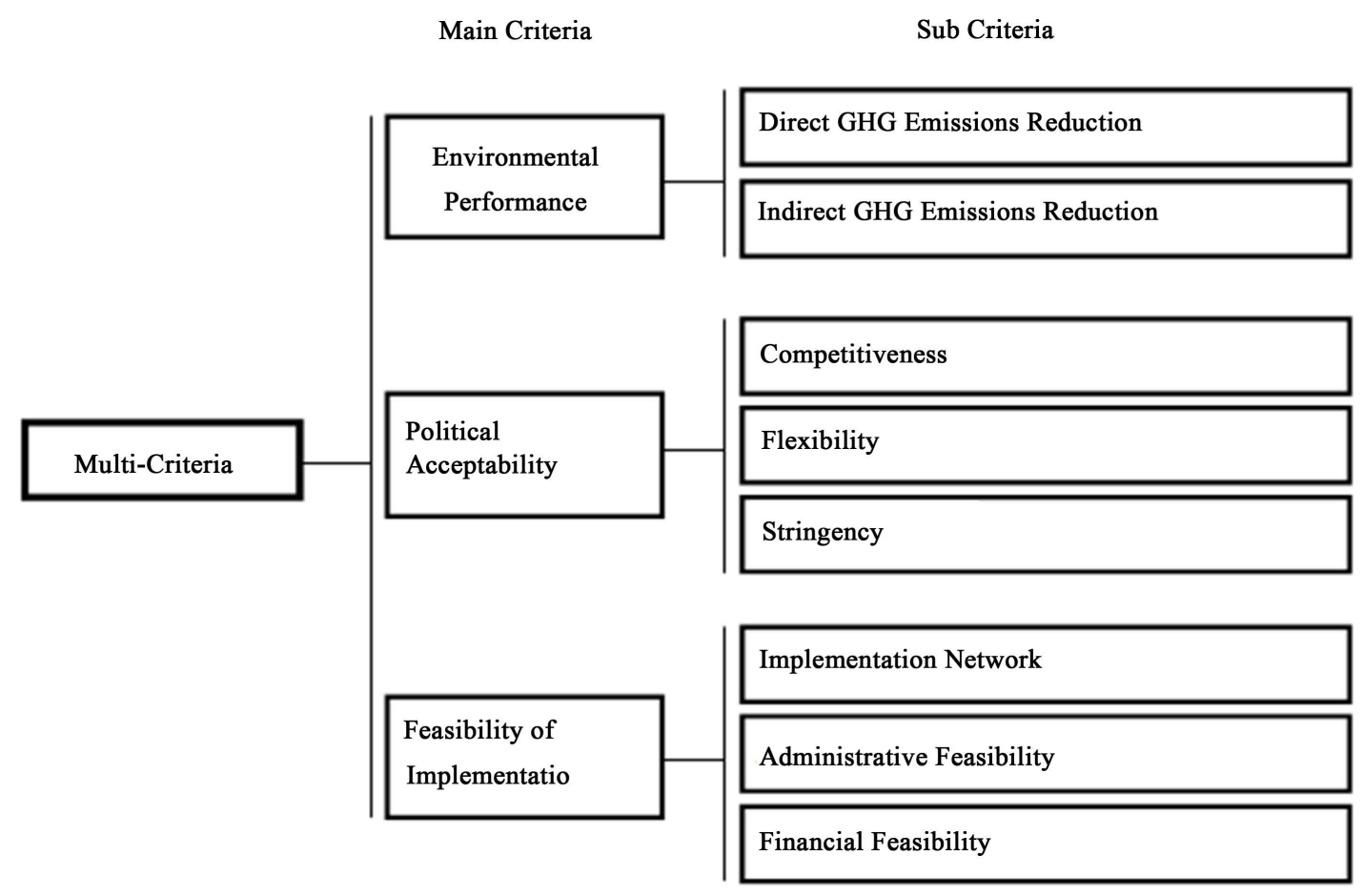

Figure 1. Flow chart of multi-criteria. Source: [9]. 
a) Command \& Control Approach: The "command and control” approach follows enforcement of the existing regulations by compulsion and coercion where polluters are penalized if failed to comply with discharge/ emission standard. The present national policy and rules are not adequately harmonized with the needs and capabilities of regulatory institutions and industries (3R Strategy, 2010, p. 5). Merely coercion without assistance (e.g. financial, technical) and cooperation (e.g. technology transfer) to the industries may not motivate the respective top management of the industries to adopt any measures of RECP strategy.

b) Lack of Incentives: No incentive or support is available from government to promote and support cleaner production practices amongst the industries (3R Strategy, 2010, p. 5). Even industries do not get any financial support for the import of energy efficient and cleaner technology.

c) Lack of Institutional Capacity: In order to implement the policy measures outlined in the policies the respective institutions are not capable in terms of technical capacity and human resources (stakeholder consultation, 2013).The personnel of the regulatory institutions during consultation replied that there are lack of experts of the regulatory institutions (Department of Environment, Ministry of Industry, and Ministry of Power, Energy \& Mineral Resources) on energy efficiency and cleaner production measures.

d) Lack of Coordination: There is lack of coordination among the government institutions in implementing different policy measures outlined in the policies (Stakeholder Consultation, 2013). The DoE has introduced the National Environmental Policy, the Ministry of Industry has formulated Industrial Policy and the Ministry of Power, Energy \& Mineral Resources has instigated a National Energy Policy, but there have been no steps taken to initiate any integrated actions to promote energy efficiency and cleaner production measures in the country so far (Stakeholder Consultation, 2013). In this case, the private sector stakeholders (e.g. enterprises, national NGOs, civil society, and banks) can come forwards in order to build up coordination between the ministries and the relevant international organizations (e.g. UNIDO, UNEP, international donor organizations).

e) Lack of Awareness, Education \& Training: The owners/managers of the industries give less priority taking the relevant measures like energy efficiency and pollution prevention. This happens because of not having clear knowledge about the social, environmental and economic benefits of adopting any measures of RECP. Besides, the respective regulatory authorities did not take any initiatives to make industries aware of the benefits of energy efficient and cleaner production measures. No academic programmes related to RECP are offered at any educational institutions in Bangladesh although there are courses related to both energy and environment. There are limited training institutions which provide training on energy efficiency and cleaner production to the staffs of the industries in the country.

f) Lack of Finance: The GoB does not provide any financial support to the industries in line with the adoption of any measures like energy efficiency and cleaner production. Therefore industries also do not get any financial support (e.g. soft loan, tax \& vat reduction) to import energy efficient and environmentally sound technologies. Moreover, financing institutions (e.g. Bank) do not have a sound knowledge regarding economic benefit of adopting the measures of energy efficiency and cleaner production to provide financial support to the industries.

g) Lower Tariff of Electricity and Natural Gas: The price of electricity and natural gas supplied to the industries is comparatively cheaper. The production cost of electricity generated in the captive power plant by natural gas in most of the manufacturing industries is BDT 2.5 per kWh. The study of IFC [8] indicated that the utility cost of the industries in Bangladesh has less significance on the overall production cost and productivity. As a result, measures to bring in efficiency in energy consumption get little or no importance to the entrepreneurs [8]. An energy advisor of the Ministry of Power, Energy \& Mineral Resources during stakeholder consultation has also replied that due to the lower tariff of electricity and natural gas the owner of an industry gives less priority on adopting any measures for energy efficiency.

\subsection{Lessons Learnt from the Review of the Regional Initiatives}

From the review it has been seen that a mix of policy instruments have been applied in the three countries (Thailand, Vietnam and Philippines). It has been observed that these countries have been following the policy instruments which are mostly motivating and supportive. Based on the review of regional initiatives, the measures adopted by those countries are summarized as follows:

- Setting Realistic Policy Objective and Target: 
Each policy should have realistic policy objective and target delineating a specific timeline. Thailand has made "20 Years Energy Efficiency Development Plan (2011-2030)" with the target of reducing energy intensity by $25 \%$ in 2030 compared with that in 2005 through increasing energy efficiency in all sectors. Vietnam has made "the Strategy on Cleaner Industrial Production to 2020" with the target of 50\% of industrial production establishments shall adopt cleaner production by 2020.

- Application of Mix of Policy Instrument (reward/penalty, motivate \& support):

There can be seen that there are mix of regulatory, motivating and supporting policy instruments in Thailand and Vietnam. Philippines have in most cases applied motivating and supporting policy instruments. Under the regulatory policy instruments the government can charge a penalty if the industry does not meet the provision set out in the particular policy. Cooperative policy instruments can provide reward (e.g. green certificate) if any industry obtains success in meeting the provision of the policy. Motivating (e.g. fiscal incentives, soft loan) and supporting (e.g. information, education \& Training) policy instruments influence the industry to adopt any particular measures related to resource efficient and cleaner production. The "20 Year Energy Efficiency Development Plan (2011-2030)" of Thailand consists of both regulatory and cooperative policy instruments. Enforcement of the existing Energy Conservation Promotion Act (1992), Establishment of Minimum Energy Performance Standards (MEPS) and Energy Efficiency Labeling are the three regulatory policy instruments under the above plan. Funding for the amount of energy saving achieved is the cooperative policy instrument. Vietnam has formulated the Law on Economical and Efficient Use of Energy in 2010 where economic, research \& educational, cooperation and informational instruments have been included as the measures of the law. In "The Strategy on Cleaner Industrial Production to 2020" of Vietnam, establishment of information center, providing technical assistance, building up a network of organizations, and financing are the policy instruments illustrated in the strategy. Philippines has also applied different cooperative policy instruments such as Economic (e.g. environmental financing), Research \& Educational (e.g. awareness \& training), Cooperation (e.g. regional cooperation) and Informational (e.g. national cleaner production center) through executing different projects, programs and efforts.

- Establishment of Focal Point:

Establishing a focal point under the relevant ministry of the government works as a center of information dissemination related to resource efficiency and cleaner production application and measures. Enterprises can come to the information center (focal point) for any relevant query and advice. Having one place where a company can get comprehensive information reduces the time required to get appropriate information which is more efficient for the company. In Thailand the Energy Policy and Planning Office (EPPO) and the Department of Alternative Energy Development and Efficiency are the two relevant focal points under the Ministry of Energy. Vietnam has a National Cleaner Production Centre which provides training, advice and information related to Cleaner Production and other related services to businesses, ministries, chambers of commerce and international development partners. In Philippines there has Pollution Prevention Roundtable (P3R) ${ }^{7}$ as a focal point which works to increase awareness of the need for, and benefits of Cleaner Production.

- Priority on Awareness Raising, Training, Education and Research Program:

Research and development policy instrument has been applied in Thailand, Vietnam and Philippines. The policy instrument "raising awareness" among the enterprise has been followed with higher priority in the above three countries about the options of energy efficiency and cleaner production. It is important to make enterprises aware about the benefit of cleaner production and energy efficiency options. Making, entrepreneurs of the enterprises aware about the limited stock of the natural resources and the significance of conservation can motivate them to take action. It can at least send the signal that prices for resources will increase in the future. In absence of clear knowledge about the measures (EE \& CP) and lack of skilled personnel for the operation and maintenance of the measures enterprises show little interest to follow a particular policy instruments. Hence, it is necessary for the government to arrange training and capacity building program both for the staff of the enterprises and the regulatory authority. In the above three countries training and capacity building measures have been applied by the government with the aim of supporting the enterprises towards adopting energy efficiency and cleaner production measures. Internship program under the tripartite collaboration among the government, industries and universities can be considered as a remarkable initiative taken in Thailand which has been started in 1996. Under the tripartite collaboration program in Thailand, government provides fund to the universities for

http://www.p2.org/ 
the research and development of solving the problems of the industries and innovate new measures in the field of energy efficiency and cleaner production. This internship program has been able to propose 193 cleaner technology options ${ }^{8}$ during the period 2005-2008.

- Regional and International Cooperation:

Regional cooperation is essential to share the knowledge on the application of cleaner technology among the regional countries. International cooperation is required for technology transfer, financing and technical support from the developed countries to the developing countries. Asian Development Bank (ADB), World Bank (WB), European Union (EU), German Technical Cooperation (GTZ), UNIDO, UNEP, USAID and many other international organizations have come forward to help the developing Asian countries to adopt RECP strategy in the industries. Thailand, Vietnam and Philippines have made collaboration with different regional and international organizations for technology transfer, financing, technical assistance, capacity building through training and arranging education programs. For example technology transfer, a process of acquiring cleaner technologies as well as necessary knowledge and skills from developed countries. The Government of the particular country can play a pioneer role by initiating and supporting technology transfer. Developing countries like Thailand, Vietnam and Philippines have already started to follow technology transfer as a potential option of cooperation policy instruments. Bi- and/or multilateral agreements, cooperation with international development cooperation agencies, promotion of foreign direct investments, and creation of local markets for environmental technology are the major modes of applying cooperation policy instruments followed in Thailand, Vietnam and Philippines.

\subsection{Gaps in the Current Practice of Energy Management in the Ceramic Industry in Bangladesh}

a) Absence of organizational policy

Organizational policy (signed by the top management) related to corporate environmental and energy management is an expression of commitment and also a working document which will help to initiate the process of following options for energy efficiency and conservation. Most of the ceramics manufacturing industry in Bangladesh does not have their own either corporate environmental management or energy management policy or both of them with a realistic set of objectives and targets with a specific timeline for achieving them. It can be mentioned that there are no legal binding which require enterprises having a corporate environmental and energy management policy. RAK Ceramics has formulated an Environmental Policy which has been signed by the top management but there are no target oriented visions and missions in their policy. No separate energy management policy has been made in the RAK Ceramics Bangladesh Ltd.

b) Absence of organization/delegated personnel with responsibility

Organization and/or separate department consist of relevant skilled/trained personnel with clear delegation of responsibility are considered necessary to implement policy and measure progress in reaching targets. RAK Ceramics has employed personnel to deal with the issue of the Environmental Policy but clear delegation of responsibility, particularly for energy efficiency and conservation, throughout the management structure has not been established.

c) Lack of documentation regarding the result of the measures taken

Documentation is essential to record achievements gained from each EE option applied to get efficient utilization of energy. Documentation gives information which helps to get further action through drawing the attention of the top management. Documentation also assists to take corrective measures and facilitate taking investment decision for new measures. Monitoring and evaluation of the energy management options applied through documentation were not in practice at RAK Ceramics (Bangladesh) Ltd.

d) Marketing/information dissemination

In Bangladesh there is no particular focal point (like a National Cleaner Production Centre in Vietnam) where enterprises can come for advice regarding any options of energy management. A focal point will serve enterprises by providing information on energy auditing, EE measures, financing sources and ways of monitoring and evaluation of the measures applied. In order to motivate more enterprises towards the practice of energy management, the achievements of enterprises (like RAK Ceramics Bangladesh Ltd.) with energy management can be disseminated through leaflets, brochures and arranging conferences and seminars.

\footnotetext{
${ }^{8}$ Mungcharoen, T. (2009), “3R Policy and Related Activities in Thailand”, in Kojima, M. and E. Damanhuri (eds.), 3R Policies for Southeast and East Asia. ERIA Research Project Report 2008-6-1, pp. 99-106. Jakarta: ERIA.
} 
e) Complexity of technological renovation

Cleaner technology is not readily available in Bangladesh. Enterprises are solely dependent on imported technology. Therefore enterprises particularly SMEs find it difficult to conduct any technological renovation. Besides, there is also a lack of technical experts on RECP. Enterprises think that technological renovation may hamper their continuous production.

\subsection{Identification of Policy Instruments}

The existing policy instruments are not enough to promote RECP measures (EE and $\mathrm{CP}$ ) in the industries of Bangladesh. The review of regional initiatives also provides suggestions for the formulation of relevant policy instruments. Gaps in the current energy management practice of ceramics manufacturing sector identified during the case study also give some indications towards the formulation of the relevant policy instruments. From the stakeholder consultations inputs were also made to help formulate relevant policy instruments in order to motivate the enterprise to adopt different RECP options. Based on the review of regional initiatives, case study, and stakeholder consultation eleven policy instruments have been identified (Table 1).

\subsection{Evaluation of Policy Instruments}

It can be mentioned that the performance of each policy instrument depends on the right selection according to the intended policy target of a country. Evaluation of policy instruments can be done by the policy makers to select the most appropriate policy instruments for the specific country [10]. Evaluation of policy instruments is also done in verifying the results and impacts of instruments in achieving policy objectives [11]. Evaluation of policy instruments assists the government in identifying and optimizing the dynamics of policy instruments more effectively [12]. Konidari and Mavrakis (2007) have applied multi-criteria evaluation method for the quantitative evaluation of climate change mitigation policy instruments [9]. Blechinger and Shah (2011) have followed multi-criteria evaluation of policy instruments to find out appropriate policy instruments for climate change mitigation in the power generation sector of Trinidad and Tobago [13]. Multi-criteria evaluation method is also used to measure the performance of each policy instruments in connection with the respective policy targets. The evaluation of the policy instruments based on multi-criteria can assist the policy maker in selecting appropriate policy instruments based on the policy targets of Bangladesh.

In order to evaluate the policy instruments identified five representatives from the relevant stakeholder groups (academician, policy maker, enterprise, environmental specialist, and consultant) have been consulted to ascertain appropriate policy instruments with the target of low carbon industrial development within RECP framework. Following the multi-criteria evaluation method applied by Konidari and Mavrakis [9], each policy instruments have been evaluated based on mainly three criteria: 1) Environmental Performance; 2) Political Acceptability; and 3) Feasibility of Implementation.

Table 1. Screening of policy instruments.

\begin{tabular}{|c|c|c|c|c|}
\hline Sl. No. & Policy Instruments & Regional Initiative & Case Study & Stakeholder Consultation \\
\hline 1. & Environmental Control \& Enforcement & $\sqrt{ }$ & - & $\sqrt{ }$ \\
\hline 2. & Environmental Financing & $\sqrt{ }$ & $\sqrt{ }$ & $\sqrt{ }$ \\
\hline 3. & Research \& Development & $\sqrt{ }$ & $\sqrt{ }$ & $\sqrt{ }$ \\
\hline 4. & Education \& Training & $\sqrt{ }$ & $\sqrt{ }$ & $\sqrt{ }$ \\
\hline 5. & Technology Transfer & $\sqrt{ }$ & $\sqrt{ }$ & $\sqrt{ }$ \\
\hline 6. & Eco labeling & $\sqrt{ }$ & - & $\sqrt{ }$ \\
\hline 7. & Information Centre & $\sqrt{ }$ & $\sqrt{ }$ & $\sqrt{ }$ \\
\hline 8. & Awareness Building & $\sqrt{ }$ & $\sqrt{ }$ & $\sqrt{ }$ \\
\hline 9. & Fiscal Incentives & $\sqrt{ }$ & $\sqrt{ }$ & $\sqrt{ }$ \\
\hline 10. & Restructure Energy Tariff & - & - & $\sqrt{ }$ \\
\hline 11. & Regional and International Cooperation & $\sqrt{ }$ & $\sqrt{ }$ & $\sqrt{ }$ \\
\hline
\end{tabular}

Note: “ل” refers suggested policy instrument; “-” refers not suggest. 
According to the evaluation of policy instruments (Table 2), it can be seen that six policy instruments (regional \& international cooperation, fiscal incentives, awareness building, technology transfer, education \& training and environmental financing) have obtained more than eighty weighting value. Fiscal incentives have been given the first priority by the stakeholders (Figure 2). Awareness building and environmental financing have been given the second and third highest priority respectively by the stakeholders. On the contrary, research and development have been given seventh highest priority as a policy instruments which obtained weighting value seventy seven. Restructure of energy tariff for industries has been given the lowest priority as a policy instrument. The identified seven policy instruments have been briefly elaborated in the following sections:

1) Fiscal Incentive: Fiscal incentive includes subsidy, freeing import tax, income tax exemption for promoting resource efficient and cleaner technologies. Bangladesh has achieved success in disseminating solar home system (SHS) by providing fiscal incentives under the renewable energy policy. The GoB has already achieved the program's target of disseminating SHS in the off grid rural areas. The initial target of disseminating 50,000 SHS

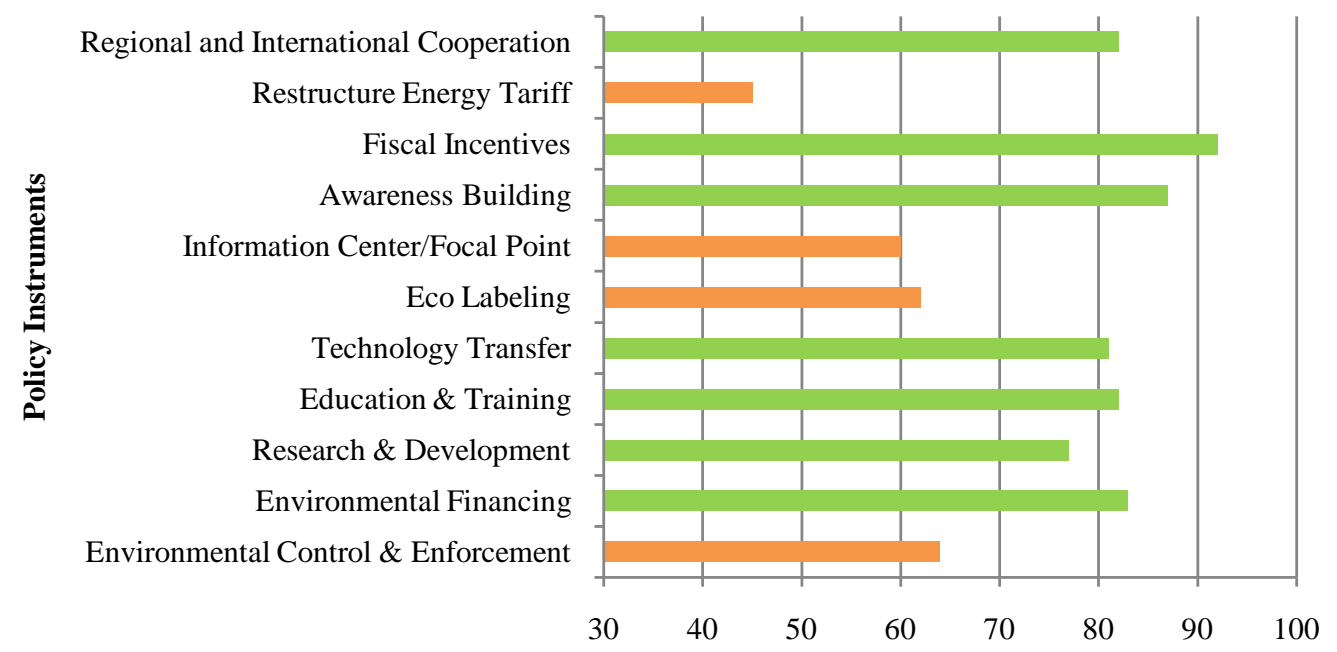

Figure 2. Preferred policy instruments suggested by the stakeholders.

Table 2. Ranking policy instruments based on the sum of weighting value.

\begin{tabular}{|c|c|c|c|c|c|c|}
\hline Policy Instruments & Academician & Policy Maker & Enterprise & Consultant & $\begin{array}{c}\text { Environmental } \\
\text { Specialist }\end{array}$ & Total Value \\
\hline $\begin{array}{c}\text { Regional and } \\
\text { International Cooperation }\end{array}$ & 18 & 18 & 13 & 15 & 18 & 82 \\
\hline Restructure Energy Tariff & 0 & 9 & 11 & 16 & 9 & 45 \\
\hline Fiscal Incentives & 19 & 17 & 20 & 18 & 18 & 92 \\
\hline Awareness Building & 13 & 19 & 17 & 19 & 19 & 87 \\
\hline Information Centre/Focal Point & 9 & 13 & 13 & 12 & 13 & 60 \\
\hline Eco labeling & 13 & 13 & 12 & 12 & 12 & 62 \\
\hline Technology Transfer & 17 & 15 & 17 & 17 & 15 & 81 \\
\hline Education \& Training & 17 & 15 & 15 & 18 & 17 & 82 \\
\hline Research \& Development & 15 & 15 & 13 & 16 & 18 & 77 \\
\hline Environmental Financing & 16 & 17 & 15 & 18 & 17 & 83 \\
\hline $\begin{array}{l}\text { Environmental Control } \\
\text { \& Enforcement }\end{array}$ & 13 & 11 & 12 & 17 & 11 & 64 \\
\hline
\end{tabular}

Source: Stakeholder consultation, 2013. 
was achieved in August 2005. Up to November 2013, 2.67 million SHS have been installed and now the government has set the target of installing 6 million SHS by the year $2016^{9}$. This means that the provision of fiscal incentives to the enterprises for the adoption of energy efficient and cleaner technologies can be an appropriate policy instruments in Bangladesh.

2) Awareness Building: This includes making the enterprises, consumers, investors, government departments and the other relevant stakeholders regarding aware of the RECP options and the associated social, environmental and economic benefits.

3) Environmental Financing: Through this policy instrument the interested industries will get soft loans and/or grants from financing institutions (e.g. Banks) for adopting any measures related to the prevention of environmental pollution, importing resource efficient and cleaner technology and doing renovation for energy efficiency. The GoB by the help of the central bank can arrange the environmental financing programmes with the participation of the national and international financing institutions.

4) Education and Training: Education and training are required for capacity building of the respective stakeholders (e.g. industries, regulatory institutions) and interested parties for promoting energy efficiency and cleaner production measures. The personnel after education and training should be able to solve the problems of energy management and cleaner production practices in their relevant discipline. They should be able for critical thinking and innovating new solutions.

5) Regional and International Cooperation: This policy instrument includes cooperation among the regional countries and building linkages with international institutions for financing, technology transfer and technical support. UNIDO and UNEP [5] have been jointly co-operating the industries in developing and transition countries for the advancement of sustainable industrial development under the RECP program ${ }^{10}$.

6) Technology Transfer: Technology transfer means importing technologies from the developed and regional countries. Technology transfer also includes getting technical support from the developed countries and regional countries. In this case, the GoB has to take initiatives to make cooperation with developed and regional countries to import energy efficient and cleaner technologies.

7) Research and Development: The aim of research and development is to conduct investigatory work to enhance stock of knowledge and to use such knowledge for the innovation of cleaner technology. If a problem (technical and non-technical) arises related to energy efficiency, energy management, and cleaner production in an industry, the industry will then report to the research institute for assistance to solve the problem. Research and development include applied research, basic research, and experimental development performed by the governmental departments, research institutes, universities, non-governmental research bodies and private companies. In Bangladesh, BCSIR is a research institute under the Ministry of Science and Technology which has been conducting research on industrial process, fuel, pollution control and so on. Many universities of Bangladesh have been providing academic program and conducting research related to the activities of the industries. No academic program on energy efficiency and cleaner production has been provided in the country.

\section{Conclusions}

The efficient consumption of energy, water and raw materials in the industrial sector has become a global issue at the context of resource constraints and climate crisis. The application of energy efficiency and cleaner production measures can contribute to prevent environmental pollution and reduce GHG emissions to ensure smooth and secure supply of raw materials, water and energy to the industries in order to keep up the continuity of economic growth. Bangladesh as one of the transition economies in the South Asia has been developed in industrial sector. Industrial sector provides the second largest share to the GDP of Bangladesh. In spite of the formulation of the environmental policies and legal frameworks the industrial pollution is still one of the major environmental problems in the country. The perceived decline of domestic natural gas has also become a major concern since natural gas is the main source of energy input in the manufacturing industries in the country. The production of natural gas in the country is decreasing gradually and it has been estimated that by the year 2030 total production of natural gas will be declined to half at current supply and consumption pattern. As a result, in order to supply uninterrupted energy to the industries, the GoB has planned to use coal for the power generation in the country. However, coal is a carbon intensive fossil fuel. There has been created a dispute regarding the

${ }^{9}$ http://www.idcol.org/energyProject.php (Accessed on 1 December 2014)

${ }^{10} \underline{h t t p: / / r e c p n e t . o r g / p a g e / a b o u t-u s ~(A c c e s s e d ~ o n ~} 25$ November 2013) 
use of coal for power generation in the country. Hence, the application of energy efficiency and cleaner production measures from now can save energy as well as prevent environmental pollution which will facilitate low carbon industrial development in the country and reduce tensions about the use of coal. The application of RECP in the industries (energy intensive industries in particular) can help to attain energy saving and prevent environmental pollution simultaneously. The study done by IFC (2012) has identified significant market potential in the industries of Bangladesh for sustainable energy finance for the financing institutions [8].

Based on the review of the existing policies, it has been seen that the GoB has formulated a number of appropriate policies which can be used to promote energy efficiency: National Environmental Policy (1992, revised in 2013), National Energy Policy (1995), Renewable Energy Policy (2008) and National Industrial Policy (2005, revised in 2010). There are no specific policies related to EE and CP in Bangladesh. No study has been conducted so far for the performance evaluation of the policies and the policy measures. A limited number of policy instruments have been included in those policies. Among those policy instruments, environmental control and enforcement have been mostly followed in the country. The GoB has been providing fiscal incentives through tax exemption for businesses to supply (or import of) renewable energy technologies. The GoB has established the Bangladesh Council for Scientific and industrial Research (BCSIR) organization to perform research on alternative fuel and fuel efficiency, pollution prevention measures, industrial processes and so on. The existing policy instruments need to be implemented properly. Command \& control approach, lack of incentive, lack of institutional capacity \& coordination, lack of awareness, education \& training and lack of finance were found major barriers to promote low carbon industry within RECP framework in Bangladesh.

Through this study, eleven policy instruments have been identified for the application of RECP options. Among the eleven policy instruments seven policy instruments have been given total ranking value more than seventy by the stakeholders for multi-criteria evaluation of policy instruments which are as follows:

1) Fiscal incentive;

2) Awareness building;

3) Environmental financing;

4) Education and training;

5) Regional and international cooperation;

6) Technology transfer; and

7) Research and development.

The above stated seven policy instruments have been identified as prioritized policy instruments to promote low carbon industrial development in Bangladesh following RECP framework. This means that the policy makers of Bangladesh have to prioritize particular policy instruments on the basis of environmental performance, political acceptability and feasibility of implementation.

\section{Acknowledgements}

The author is very much indebted to the Government of The Netherlands for giving NFP fellowship to the author to support his study M.Sc. in Environmental and Energy Management at University of Twente in Netherlands. The Author is grateful to his supervisor Dr. Joy Clancy who guided the author to do this research work.

\section{References}

[1] Giljum, S., Dittrich, M., Bringezu, S., Polzin, C. and Lutter, S. (2010) Resource Use and Resource Productivity in Asia: Trends over the Past 25 Years. Sustainable Europe Research Institute, Vienna.

[2] United Nations Industrial Development Organization (UNIDO) (2010) Resource Productivity for Climate Action. Cleaner Production Unit, Environmental Management Branch, UNIDO, Vienna, Austria. http://www.unido.org/fileadmin/user_media/Services/Environmental_Management/Cleaner_Production/Resource_prod uctivity_Climate_Action.pdf

[3] Huhne, C. (2011) The Economics of Climate Change, Speech by Secretary of State for Energy and Climate Change, 29 June 2011.

https://www.gov.uk/government/speeches/the-rt-hon-chris-huhne-mp-speech-the-economics-of-climate-change

[4] Stern, N. (2011) The Low-Carbon Industrial Revolution. Power Point Presentation, Grantham Research Institute on Climate Change and the Environment, LSE. http://www2.lse.ac.uk/publicEvents/pdf/20110317\%20Nick\%20Stern\%20ppt.pdfS 
[5] United Nations Environment Program (UNEP) (2013) Resource Efficiency and Cleaner Production UNEP, Division of Technology, Industry and Economics, Sustainable Consumption \& Production Branch. http://www.unep.fr/scp/cp/

[6] Almeida, C.M.V.B., Bonilla, S.H., Giannetti, B.F. and Huisingh, D. (2013) Cleaner Production Initiatives and Challenges for a Sustainable World: An Introduction to this Special Volume. Journal of Cleaner Production, 47, 1-10. http://dx.doi.org/10.1016/j.jclepro.2013.03.010

[7] Ministry of Finance (MoF) (2012) Bangladesh Economic Review FY 2012-13. Dhaka, Bangladesh: Finance Division, Ministry of Finance, Government of Bangladesh. http://www.mof.gov.bd/en/index.php?option=com content\&view=article\&id=210\&Itemid=1

[8] IFC (2012) Industry Specific Study on Sustainable Energy Finance Market Potential for Financial Institutions in Bangladesh. South Asia Enterprise Development Facility Project, International Finance Corporation (IFC), World Bank Group.

http://www.ifc.org/wps/wcm/connect/064ec0804129f3328d67bddf0d0e71af/SEF+Market+potential+study+Banglades h.pdf?MOD=AJPERES

[9] Konidari, P. and Mavrakis, D. (2007) A Multi-Criteria Evaluation Method for Climate Change Mitigation Policy Instruments. National and Kapodistrian University of Athens, Environmental Policy Group, Panepistimiopolis, KEPA Building, 15784 Athens, Greece.

[10] SYKE (Finnish Environment Institute) (2007) Assessing the Adaptive Capacity of the Finnish Environment and Society under a Changing Climate: FINADAPT. Summary for Policy Makers written by Timothy R. Carter, Helsinki.

[11] Neij, L. and Astrand, K. (2006) Outcome Indicators for the Evaluation of Energy Policy Instruments and Technical Change. Energy Policy, 34, 2662-2676. http://dx.doi.org/10.1016/j.enpol.2005.03.012

[12] VROM, Netherlands Ministry of Housing, Spatial Planning and the Environment (2005) Climate Policy Evaluation Memorandum 2005, On the Way to Kyoto, an Evaluation of Dutch Climate Policy Aimed at Meeting the Kyoto Protocol Commitments. http://www.lowcarbonoptions.net/resources/Policy-\&-Measures/Policies-and-Measures--Netherlands/Kyoto.pdf

[13] Blechinger, P.F.H. and Shah, K.U. (2011) A Multi-Criteria Evaluation of Policy Instruments for Climate Change Mitigation in the Power Generation Sector of Trinidad and Tobago. Energy Policy, 39, 6331-6343.

http://dx.doi.org/10.1016/j.enpol.2011.07.034 